\title{
Analysis of Hydraulic System on Portable Electrical Hydraulic Jack
}

\author{
Rinasa Agistya Anugrah ${ }^{1, *}$, Putri Rachmawati ${ }^{2}$ \\ ${ }^{1,2}$ Department of Mechanical Technology, Universitas Muhammadiyah Yogyakarta, Indonesia \\ ${ }^{*}$ Corresponding author. Email: rinasaanugrah@umy.ac.id
}

\begin{abstract}
Hydraulic systems have been widely used in several large industries, the use of hydraulics in industrial activities help the running of related industrial activities. A large number of maintenance requests for the workshop requires a modern jack that can increase work productivity in the workshop. Also, designing a hydraulic jack to increasing its ability to make it easier, faster, and more modern in operation. A hydraulic jack is made to consider the work safety factor of workers who use it. In this study also improves the hydraulic jack capability better, namely analyzing the hydraulic system parts or hydraulic telescopic capabilities on a portable electrical hydraulic jack. In this research, the method to analyze the lift force is to use Pascal's Law Concept. The maximum initial force mechanism to lift the load on the lifting hydraulic pump is $5.35 \mathrm{~kg}$ or in a percentage of about $0,38 \%$ of the load. Then, the position of the hydraulic cylinder tilt angle before working is $11.53^{\circ}$, while the position of the hydraulic cylinder tilt angle in maximum extension is $40.83^{\circ}$. Linear trend on height of jack, length of hydraulic cylinder, and angle of inclination indicate the hydraulic system of the portable electrical hydraulic jack is work very well.
\end{abstract}

Keywords- Hydraulic System, Hydraulic Cylinder, Angle of Inclination, Height of Jack, Lift Force

\section{INTRODUCTION}

Nowadays hydraulic systems have been widely used in several large industries, the use of hydraulics in industrial activities really helps the running of related industrial activities. The application of hydraulic systems is usually used in various fields of the food industry, beverage industry, machinery industry, automotive industry, to the robot manufacturing industry, and building construction industry. So that knowledge of the components of a hydraulic system is very important in all branches of industry. To increase the effectiveness and productivity of this system, it is necessary to have a hydraulic system that can be combined with other systems such as mechanics, so that more optimal performance will be obtained [1].

One of the uses of the hydraulic system used in the automotive industry is a hydraulic jack [1], [2]. By increasing the ability of the hydraulic jack it is expected to increase work productivity which is getting higher [2]. In 2020 car sales in Europe reached nearly 14 million, although there was a decline from 2019, which was 18 million due to the Covid-19 pandemic [3]. By looking at the large number of cars circulating to consumers, it can be concluded that tens of millions is a large number. and this is a potential business in the workshop. Which equipment such as hydraulic jack is a must that must be fulfilled by the workshop owner. The large number of maintenance requests for the workshop requires a modern jack that can increase work productivity in the workshop.
In every car repair shop in Indonesia, both official and non-official, almost every repair shop has a jack as a tool to assist mechanics in repairing car components. In developing technology in the hydraulic field, an analysis is needed that can produce a product with the best quality and get work effectiveness to meet the quality of production results. Among them are using a hydraulic system on a manual jack and modified into a hydraulic jack. A hydraulic jack is a mechanical means for raising a car that works with fluid. In implementing its function, the jack is a support that accepts the car's load. In Indonesia, the working principle of the hydraulic jack that is used generally still uses manual drive or human power.

Likewise, the hydraulic jack application in the construction industry. In one study, they designed a multipurpose hydraulic tool for door installation, for door and gate installations and for moving goods, because it is equipped with wheels on this hydraulic jack. This tool can shorten the installation work time by up to two times faster for plastic and wooden doors, while the installation of the gate is one and a half times faster. In fact, this work can be done by half of the number of workers who use ordinary jacks [4].

Therefore, design development is very important and is always done to increase the ability of the jack and accelerate the work productivity of the workers. Like only development through numerical research or simulation with computers to solve problems by predicting through theory and numerical calculations and then adding an automation system to the 
jack [5]. The problem that often occurs is the length of time installed or working with the hydraulic jack, so it is necessary to make it easier to use the jack which is then made automated. The designs are developed and made more compact but have better capabilities [6]-[9].

In designing a hydraulic jack in addition to increasing its ability to make it easier, faster, and more modern in operation, a hydraulic jack is made to also consider the work safety factor of the workers who use it [10], [11]. Several studies have developed towards the use of renewable energy as a source of electricity from hydraulic jack drives with solar cells, one of which is a study that combines a bottle jack with an electric motor drive, the source of which is a battery whose electric current is supplied by solar cells [10]. So that in this study also improve the hydraulic jack capability better, namely analyzing the hydraulic system parts or hydraulic telescopic (hydraulic cylinder) capabilities on portable electrical hydraulic jack. The design and analytical for capability of lifting forces have been discussed in paper published before [12].

\section{RESEARCH METHODS}

Design of frame of portable electrical hydraulic jack in 3D form is shown in Figure 1 below. The jack is using for automotive vehicles when they will have been being repaired from the ground of them. It is powered by an electrical motor drive for giving some energy to lift it when it will be used.

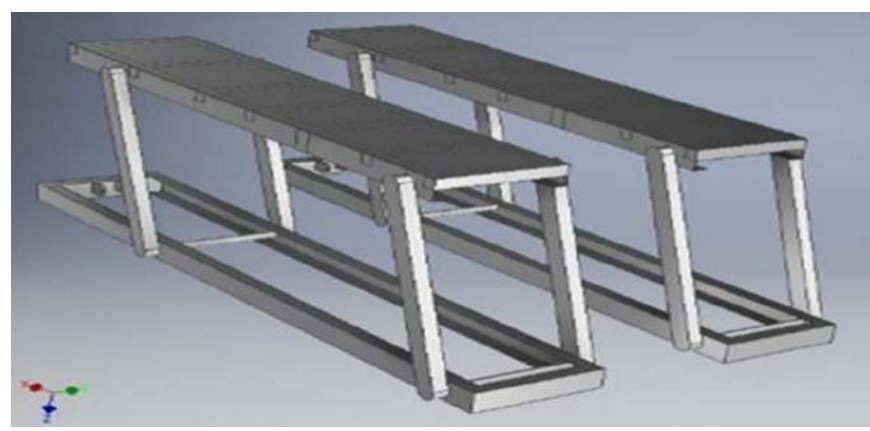

Figure 1 3D Form Design of Frame of Portable Electrical Hydraulic Jack [12]

In this research, the method to calculate the lift force using Pascal's Law Concept, namely the pressure will be the same in a hydraulic system. There is a difference in the entry and exit forces due to the piston cross-sectional area. Equations 1 to 5 are used in this paper.

$$
\begin{aligned}
& p_{1}=p_{2} \\
& \frac{\mathrm{F}_{1}}{\mathrm{~A}_{1}}=\frac{\mathrm{F}_{2}}{\mathrm{~A}_{2}} \\
& \mathrm{~F}_{2}=\frac{\mathrm{F}_{1} \times \mathrm{A}_{2}}{\mathrm{~A}_{1}} \\
& \mathrm{~F}_{2}=\frac{\mathrm{F}_{1} \times \pi \cdot \mathrm{r}_{2}^{2}}{\pi \cdot \mathrm{r}_{1}^{2}}
\end{aligned}
$$

$$
\mathrm{F}_{2}=\frac{\mathrm{F}_{1} \times \mathrm{r}_{2}^{2}}{\mathrm{r}_{1}^{2}}
$$

The information of the equations:

$$
\mathrm{p}_{1}=\mathrm{p} 2=\text { Pressure }
$$

$\mathrm{F}_{1}=$ Force on piston pump

$\mathrm{F}_{2}=$ Lifting Force of Electrical Hydraulic Jack

$\mathrm{A}_{1}=$ Cross-sectional area of piston pump

$\mathrm{A}_{2}=$ Cross-sectional area of piston valve in outlet pump

$\mathrm{r}_{1}=$ Radius of input piston

$\mathrm{r}_{2}=$ Radius of output piston

Then, by using the concept of pascal, a scheme like the following is created in Figure 2.

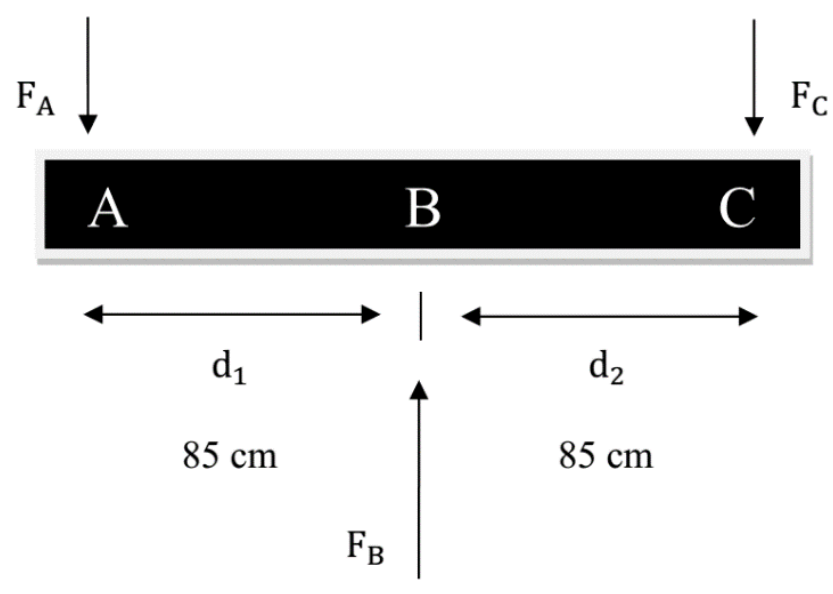

Figure 2 Concept of Pascal Law to Calculate Lifting force

The balance term is $\sum \mathrm{M}_{\mathrm{B}}=0$

$$
\begin{aligned}
& =\left(F_{A} \cdot X_{1}\right)-\left(F_{C} \cdot X_{2}\right) \\
& =(4570 \cdot 0,85)-(4570 \cdot 0,85) \\
& =3884,5-3884,5 \\
& =0 \text { (in balance) }
\end{aligned}
$$

From the kinematic analysis that occurs in the principle of equilibrium, the results of the magnitude of the force at each fulcrum are $466.67 \mathrm{~kg}=4.57 \mathrm{kN}$ in units of $\mathrm{g}=9.8 \mathrm{~m} / \mathrm{s}^{2}$ and the workpiece balance, the moment of force at the point $\mathrm{B}\left(\mathrm{M}_{\mathrm{B}}=0\right)$.

The method of calculation the angle of inclination of the hydraulic cylinder are as follows :

1. Measure the height of the jack.

2. Measure the length of the hydraulic cylinder.

3. Use arcus trigonometry of sinus, the ratio of sinus is the dividing of height of the jack with the length of hydraulic cylinder.

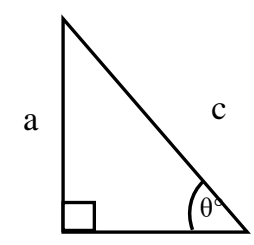

b 
Figure 3 Concept of trigonometry to calculate the angle of inclination

Based on Figure 3 above so can be used the equation with principal of arcus sinus as following equation 6 and 7 .

$$
\begin{aligned}
& \sin \theta^{\circ}=\frac{a}{c} \\
& \sin ^{-1}\left(\frac{a}{c}\right)=\theta^{\circ}
\end{aligned}
$$

\section{RESULTS AND DISCUSSION}

In accordance with the dimensions of the Hydraulic Cylinder shown in Table 1 , the actual measurements obtained from the author's measurements with the caliper are:

Table 1. Measurement Results of the Components

\begin{tabular}{|c|l|c|}
\hline No. & \multicolumn{1}{|c|}{ Components } & Length \\
\hline 1 & Outer Diameter of Hydraulic Cylinder & $6 \mathrm{~cm}$ \\
\hline 2 & Inner Diameter of Hydraulic Cylinder & $5 \mathrm{~cm}$ \\
\hline 3 & Diameter of Hydraulic Stroke & $3 \mathrm{~cm}$ \\
\hline 4 & Diameter of Piston Pump & $1,9 \mathrm{~cm}$ \\
\hline 5 & $\begin{array}{l}\text { Diameter of Piston Valve in Outlet } \\
\text { Pump }\end{array}$ & $0,6 \mathrm{~cm}$ \\
\hline 6 & Length of Hydraulic Cylinder & $8 \mathrm{~cm}$ \\
\hline 7 & Length of Hydraulic Stroke & $7 \mathrm{~cm}$ \\
\hline 8 & Thickness of Main Cylinder Wall & $1 \mathrm{~cm}$ \\
\hline
\end{tabular}

From the results of the analysis, the specification data that has known the weight of the object is $1400 \mathrm{~kg}$ and the cross-sectional area 1 has a radius of diameter $(\mathrm{r}) 3 \mathrm{~mm}=$ $0.003 \mathrm{~m}$, so it can be seen that $\mathrm{A}_{1}=0.0003 \mathrm{~m}^{2}$. While the cross-sectional area 2 has a radius of (r) $50 \mathrm{~mm}=0.05 \mathrm{~m}$, it can be seen that $\mathrm{A}_{2}=0.008 \mathrm{~m}^{2}$, because the diameter of a hydraulic cylinder has a diameter of $50 \mathrm{~mm}$ in one hydraulic cylinder while in the Electrical Portable Hydraulic Jack tool has 2 hydraulic cylinder rods. Based on the results of the analysis of the hydraulic system on the Electrical Portable Hydraulic Jack, after knowing the specification data, the power needed to lift the MPV (Multi-Purpose Vehicle) car, Testing shown in Figure 4, with a capacity of 1.4 tons requires a maximum power of $52.5 \mathrm{~N}$ or $5.35 \mathrm{~kg}$ at the initial pressure of the pump.

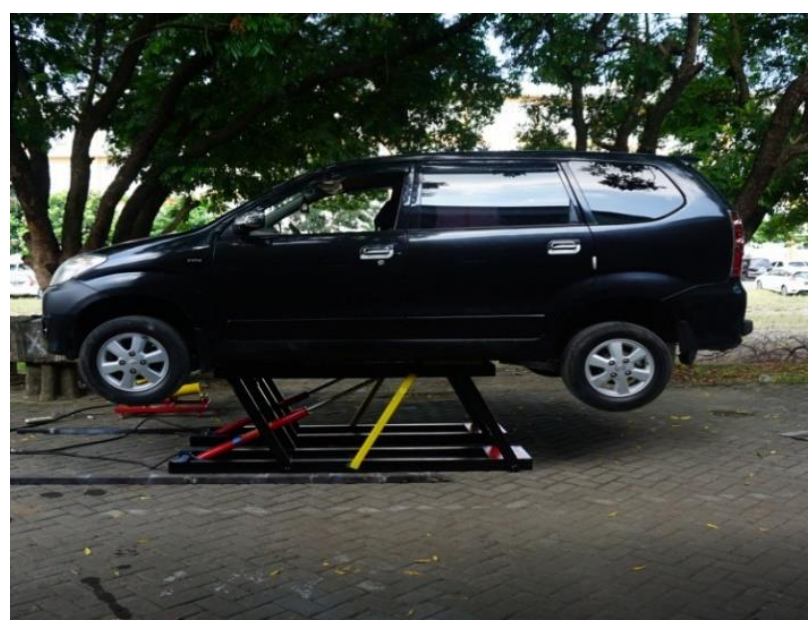

Figure 4. Testing the Portable Electrical Hydraulic Jack with an MPV Car

From the results of this analysis, there is a comparison value between the hydraulic pump and the load of the MPV car, which can be assumed in the result in Table 2 below:

Table 2. Data of Forces

\begin{tabular}{|c|c|}
\hline $\begin{array}{c}\text { F1 (Force of Hydraulic } \\
\text { pump) }\end{array}$ & F2 (weight of the MPV car) \\
\hline $5,35 \mathrm{~kg}$ & $1400 \mathrm{~kg}$ \\
\hline $1 \mathrm{~kg}$ & $262 \mathrm{~kg}$ \\
\hline
\end{tabular}

The angle of inclination (tilted angle) of the hydraulic cylinder when hydraulic telescopic have not yet working is $\theta^{\circ}=11,53^{\circ}$. The scheme to explain that is shown in Figure 5 below. How could this happen, the answer is because in the position there is no stress on the hydraulic fluid not at zero degrees because it provides a safe limit for the initial lift.

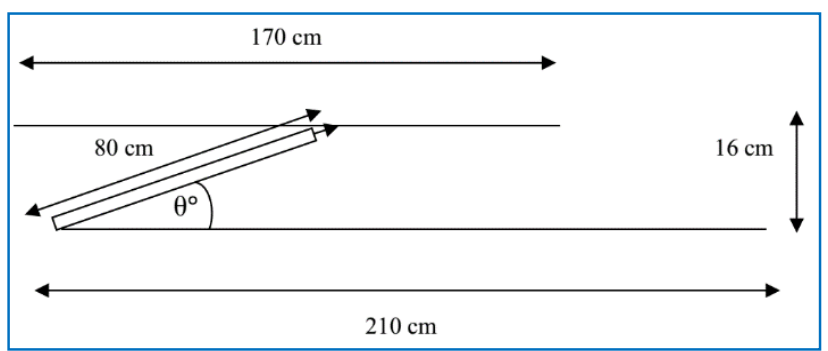

Figure 5. Tilted Angle of Hydraulic Cylinder Before Work

The angle of inclination of the hydraulic cylinder at the time of maximum hydraulic telescopic displacement is $\theta^{\circ}=$ $40,83^{\circ}$. The scheme to explain that is shown in Figure 6 below. The telescopic elongated to maximum length until stuck in position. The maximum tilt angle magnification limit is not up to 50 degrees because this point is the safe threshold of the tilt angle of a hydraulic telescopic when used. So that in this design there is a degree difference of about $18 \%$ from the safety threshold. 


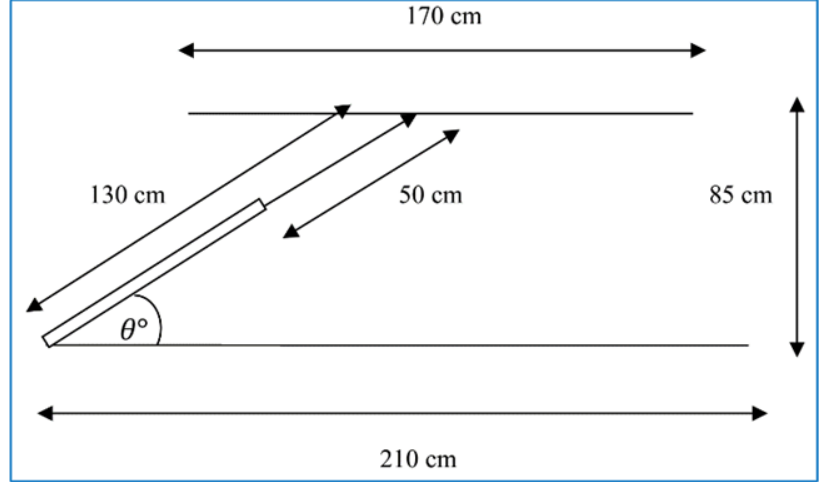

Figure 6. Tilted Angle of Hydraulic Cylinder in Maximum Extension

The telescopic design of the electrical hydraulic jack has gone through the testing phase with a load of $1400 \mathrm{~kg}$, so with calculations through the concept of Pascal's law, the force on the piston valve is only $5.35 \mathrm{~kg}$. This means that only $0.38 \%$ of the load is needed to provide the minimum force on the piston pump (jack input).

Every extension of hydraulic cylinder length is followed by increasing angle of inclination in linear comparison. Height of jack run into also in linear comparison with extension of hydraulic cylinder length and angle of inclination. All three data can be seen in Table 3 which contain of data involve of height of jack, length of hydraulic cylinder, and angle of inclination.

Table 3. Experimental Testing Data of Hydraulic Jack

\begin{tabular}{|c|c|c|c|}
\hline No & $\begin{array}{c}\text { Height of } \\
\text { Jack }(\mathbf{c m})\end{array}$ & $\begin{array}{c}\text { Length of } \\
\text { Hydraulic } \\
\text { Cylinder }(\mathbf{c m})\end{array}$ & $\begin{array}{c}\text { Angle of } \\
\left.\text { Inclination } \mathbf{(}^{\circ}\right)\end{array}$ \\
\hline 1 & 16 & 80 & 11,53 \\
\hline 2 & 20 & 82,9 & 13,96 \\
\hline 3 & 25 & 86,5 & 16,79 \\
\hline 4 & 30 & 90,1 & 19,44 \\
\hline 5 & 35 & 93,8 & 21,92 \\
\hline 6 & 40 & 97,4 & 24,25 \\
\hline 7 & 45 & 101,0 & 26,45 \\
\hline 8 & 50 & 104,6 & 28,54 \\
\hline 9 & 55 & 108,3 & 30,53 \\
\hline 10 & 60 & 111,9 & 32,43 \\
\hline 11 & 65 & 115,5 & 34,25 \\
\hline 12 & 70 & 119,1 & 35,99 \\
\hline 13 & 75 & 122,8 & 37,66 \\
\hline 14 & 80 & 126,4 & 39,27 \\
\hline 15 & 85 & 130 & 40,83 \\
\hline
\end{tabular}

The linear trend of all the data is shown on Figure 7, Figure 8 , and Figure 9. Figure 7 is graph which show comparison data of height of jack with length of hydraulic cylinder. The more increasing of height of jack the more increasing length of hydraulic cylinder in linear trend. We know that every extension of hydraulic cylinder length cause increasing of height of jack.

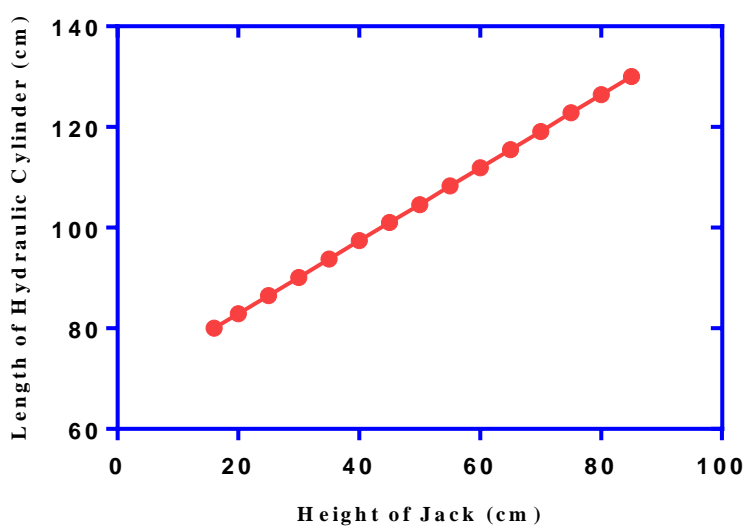

Figure 7 Comparison Height of Jack toward Length of Hydraulic Cylinder

In Figure 8, we can see the linear trend curve which is formed by data of length of hydraulic cylinder toward angle of inclination.

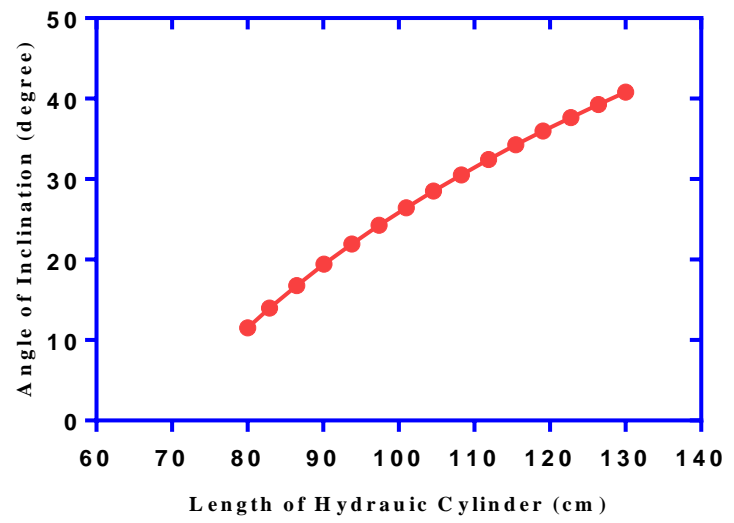

Figure 8. Comparison Length of Hydraulic Cylinder toward Angle of Inclination

If we make a graph to show a linear trend too, we have linear curve from angle of inclination and height of jack. Figure 9 is shown the case. 


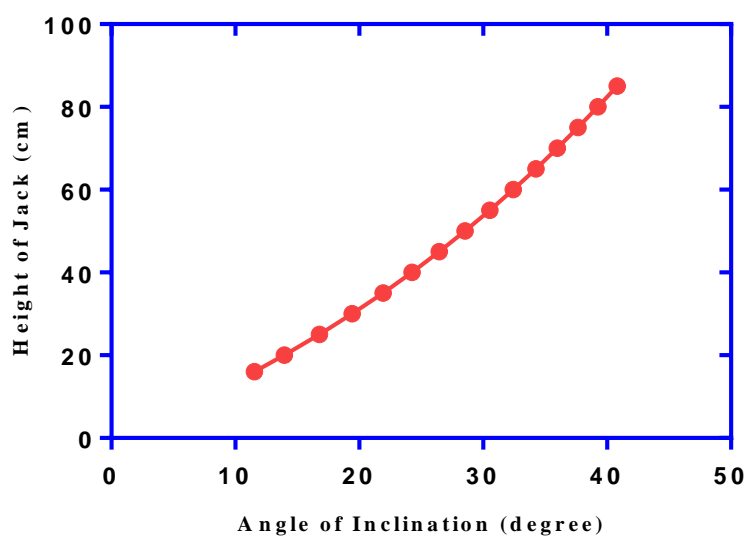

Figure 9 Comparison Angle of Inclination toward Height of Jack

All of three graphs indicate that the three parameters of retrieved data in this research the trend of linear trend in all of parameters. Linear trend on the three parameters indicate the hydraulic system of the portable electrical hydraulic jack is work very well. There is no problem with this hydraulic system.

\section{CONCLUSION}

Based on the results of calculations and discussion of research on "Analysis of Hydraulic Systems in Electrical Portable Hydraulic Jack", several conclusions can be drawn, namely:

1. The maximum initial force mechanism to lift the load on the lifting hydraulic pump is $5.35 \mathrm{~kg}$. The magnitude of the ratio between the hydraulic pump pressure and the weight of the MPV car is $5.35 \mathrm{~kg}: 1400 \mathrm{~kg}(1: 262)$ or in a percentage of about $0,38 \%$ of the load.

2. The analysis results obtained on the Electrical Portable Hydraulic Jack when the position of the hydraulic cylinder tilted angle before working is $11.53^{\circ}$, while the position of the hydraulic cylinder tilted angle in maximum extension is $40.83^{\circ}$.

3. Linear trend on the three parameters involve height of jack, length of hydraulic cylinder, and angle of inclination indicate the hydraulic system of the portable electrical hydraulic jack is work very well.

\section{ACKNOWLEDGMENTS}

Thanks to Universitas Muhammadiyah Yogyakarta that giving administration and facilitation to this publication. And Thanks to Muhammad Anivaludin Soleh, the alumnus of Department of Mechanical Technology, Universitas Muhammadiyah Yogyakarta who conducted testing and experiment of this research.

\section{REFERENCES}

[1] M. V. K. Abhinav Bhardwaj1, Amit Raj Ranjan2 and 3Assistant Professor, "Inbuilt hydraulic jack with master cylinder," Int. J. Technol. Res. Eng., vol. 7, no.
9, pp. 6818-6819, 2020, [Online]. Available: https://www.ijtre.com/images/scripts/2020070917.pdf.

[2] A. Masiwal et al., "Design and fabrication of Hydraulic Jack system for four wheelers," Int. Res. J. Eng. Technol., vol. 05, no. 04, pp. 3847-3854, 2018, [Online]. Available: https://www.irjet.net/archives/V5/i4/IRJETV5I4628.pdf.

[3] K. Head, P. Martin, and T. Mayer, "Car Wars: Competitiveness , Trade," vol. 58, no. 4, 2020, [Online]. Available: https://www.cairn-int.info/revuenotes-du-conseil-d-analyseeconomique-2020-4-page1.htm.

[4] S. S. 1 Asnizah Sahekhaini1,*, Norhayati Ibrahim 1, Bibie Sara Salleh 1 and A. A. 2, "Design of Multipurpose Hydraulic Tool for Door Installation," J. Adv. Res. Appl. Sci. Eng. Technol., vol. 1, no. 1, pp. 15, 2020, [Online]. Available: http://www.akademiabaru.com/doc/ARASETV19_N1 _P1_5.pdf.

[5] V. I. Averchenkov, A. V. Averchenkov, V. V. Kolyakinand, and O. D. Orekhov, "Issues of a computer-aided design of hydraulic jacks," IOP Conf. Ser. Mater. Sci. Eng., vol. 124, no. 1, 2016, doi: 10.1088/1757-899X/124/1/012040.

[6] A. Patil, S. Wangikar, S. Patil, and M. S. Rajashekhar, "Design and Analysis of Telescopic Jack," Int. Res. J. Eng. Technol., no. 4, pp. 1355-1361, 2016, [Online]. Available:

https://www.irjet.net/archives/V3/i7/IRJETV3I7286.pdf.

[7] P. U. Anaidhuno, S. O. Ologe, and A. E. Yerimearede, "The Design of a Simple 50 Tons Capacity Three Stage Telescopic Hydraulic Jack for Automobile and Vessel ( Ship ) Application The Design of a Simple 50 Tons Capacity Three Stage Telescopic Hydraulic Jack for Automobile and Vessel ( Ship ) Application," Eur. J. Adv. Eng. Technol., no. June 2020, 2019, [Online]. Available:

https://www.researchgate.net/publication/342145614_ The_Design_of_a_Simple_50_Tons_Capacity_Three_ Stage_Telescopic_Hydraulic_Jack_for_Automobile_a nd_Vessel_Ship_Application.

[8] M. A. A. O. J, "Development, Design, Analysis and Construction of a Digital Electronic Jack," J. Adv. Dev. , Des. , Anal. Constr. a Digit. Electron. Jack, vol. 8, no. 1, pp. 1-5, 2020.

[9] M. Agrawal, M. G. Thakur, D. Mahajan, and T. S. Chahar, "Inbuilt Hydraulic Jack System for Four Wheelers : -A new trend in automobile sector," Int. Res. J. Eng. Technol., vol. 5, no. 2, pp. 1386-1390, 2018.

[10] F. I. A. and T. C. Nwaoha2, "DESIGN AND DEVELOPMENT OF A SOLAR POWERED MOTORISED HYDRAULIC JACK FOR INDUSTRIAL AND DOMESTIC APPLICATIONS," Sci. Technol. J., vol. 4, no. 1, p. v, 2002, doi: 10.1016/b978-0-08-044050-7.50063-x.

[11] 1, 4M.Yogeshwaran R.Sureshkumar, 2V.Vijaykumar, 3R.Vinoth, and 5R.Moses Samuel, "Fabrication of 
Inbuilt Electro Hydraulic Jack for Four Wheelers," Int. J. Innov. Res. Stud., vol. 8, no. Iv, pp. 3847-3854, 2018.

[12] P. Rachmawati and I. R. Kurniawan, "Design of Portable Electric Hydraulic Jack for Improving the Productivity," J. Phys. Conf. Ser., vol. 1381, no. 1, 2019, doi: 10.1088/1742-6596/1381/1/012059. 